\title{
Effect of 1,5-anhydroglucitol levels on culprit plaque rupture in diabetic patients with acute coronary syndrome
}

\author{
Gong Su' ${ }^{1 *} \mathbb{D}$, Ming-Xi Gao ${ }^{1}$, Gen-Ling Shi ${ }^{1}$ Xi-Xi Dai ${ }^{1}$, Wei-Feng Yao ${ }^{1}$, Tao Zhang ${ }^{2}$ and Shao-Wei Zhuang ${ }^{3^{*}}$
}

\begin{abstract}
Background: Postprandial hyperglycemia was reported to play a key role in established risk factors of coronary artery diseases (CAD) and cardiovascular events. Serum 1,5-anhydroglucitol (1,5-AG) levels are known to be a clinical marker of short-term postprandial glucose (PPG) excursions. Low serum 1,5-AG levels have been associated with occurrence of CAD. However, the relationship between 1,5-AG levels and coronary plaque rupture has not been fully elucidated. The aim of this study was to evaluate 1,5-AG as a predictor of coronary plaque rupture in diabetic patients with acute coronary syndrome (ACS).

Methods: A total of 144 diabetic patients with ACS were included in this study. All patients underwent intravascular ultrasound examination, which revealed 49 patients with plaque rupture and 95 patients without plaque rupture in the culprit lesion. Fasting blood glucose (FBG), hemoglobin $\mathrm{A}_{1 c}\left(\mathrm{HbA}_{1 c}\right)$ and 1,5-AG levels were measured before coronary angiography. Fasting urinary 8-iso-prostaglandin $\mathrm{F}_{2 a}\left(8-\mathrm{iso}-\mathrm{PGF}_{2 a}\right)$ level was measured and corrected by creatinine clearance.
\end{abstract}

Results: Patients with ruptured plaque had significantly lower serum 1,5-AG levels, longer duration of diabetes, higher $\mathrm{HbA}_{1 \mathrm{c}}$ and $\mathrm{FBG}$ levels than patients without ruptured plaque in our study population. In multivariate analysis, low 1,5-AG levels were an independent predictor of plaque rupture (odds ratio $3.421 ; P=0.005$ ) in diabetic patients with ACS. The area under the receiver-operating characteristic curve for $1,5-\mathrm{AG}(0.658, \mathrm{P}=0.002)$ to predict plaque rupture was superior to that for $\mathrm{HbA}_{1 \mathrm{c}}(0.587, \mathrm{P}=0.087)$. Levels of $1,5-\mathrm{AG}$ were significantly correlated with urinary 8-iso-prostaglandin $\mathrm{F}_{2 a}$ levels $(\mathrm{r}=-0.234, \mathrm{P}=0.005)$.

Conclusions: Serum 1,5-AG may identify high risk for coronary plaque rupture in diabetic patients with ACS, which suggests PPG excursions are related to the pathogenesis of plaque rupture in diabetes.

Keywords: 1,5-Anhydroglucitol, Plaque rupture, Acute coronary syndrome, Diabetes, Intravascular ultrasound

*Correspondence: su_gong@yahoo.com; zhuangs66@yahoo.com 1 Department of Cardiovascular Medicine, Shanghai General Hospital Baoshan Branch, No. 101 Tongtai North Road, Baoshan District, Shanghai 200940, China

${ }^{3}$ Department of Cardiovascular Medicine, The Seventh People's Hospital, Shanghai University of Traditional Chinese Medicine, No. 358 Gaoqiaodatong Road, Pudong District, Shanghai 200137, China Full list of author information is available at the end of the article

\section{Background}

Acute coronary syndromes (ACS), including ST-elevation myocardial infarction (STEMI) and Non-ST-elevation acute coronary syndromes (NSTE-ACS), are a common cause of morbidity and mortality in individuals with diabetes. Autopsy data and intravascular imaging studies have showed that ACS results from spontaneous plaque rupture or erosion and subsequent thrombosis [1-3]. A meta-analysis, based on optical coherence tomography findings, showed the rate of plaque ruptures is $70.4 \%$ in

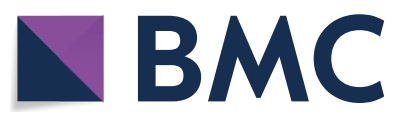

(c) The Author(s) 2020. This article is licensed under a Creative Commons Attribution 4.0 International License, which permits use, sharing, adaptation, distribution and reproduction in any medium or format, as long as you give appropriate credit to the original author(s) and the source, provide a link to the Creative Commons licence, and indicate if changes were made. The images or other third party material in this article are included in the article's Creative Commons licence, unless indicated otherwise in a credit line to the material. If material is not included in the article's Creative Commons licence and your intended use is not permitted by statutory regulation or exceeds the permitted use, you will need to obtain permission directly from the copyright holder. To view a copy of this licence, visit http://creativeco mmons.org/licenses/by/4.0/. The Creative Commons Public Domain Dedication waiver (http://creativecommons.org/publicdomain/ zero/1.0/) applies to the data made available in this article, unless otherwise stated in a credit line to the data. 
STEMI patients, $55.6 \%$ in NSTEMI patients and $39.1 \%$ in unstable angina patients, respectively [4]. In an analysis of lesions from patients after sudden coronary death, ruptured plaque is recognized to be responsible for the most of cases of acute coronary thrombi [5]. Diabetic patients are at a high risk for cardiovascular events for having more vulnerable features in both culprit and nonculprit lesions compare to patients without diabetes [6]. Many researchers are attempting to find out what factors could affect coronary plaque rupture in diabetic patients for preventing critical outcomes.

Serum 1,5-anhydroglucitol (1,5-AG) level is a clinical marker to better reflect short-term postprandial hyperglycemia and glycemic variability (GV) than do hemoglobin $\mathrm{A}_{1 \mathrm{c}}\left(\mathrm{HbA}_{1 \mathrm{c}}\right)$ level [7]. Therefore, 1,5-AG levels may be associated with cardiovascular complications in diabetes. Indeed, some studies have reported that 1,5AG levels are bound up with cardiovascular disease [8, 9]. Several clinical studies showed that 1,5-AG levels had utility to predict cardiovascular events in study population [10-12]. However, the association between 1,5-AG levels and coronary plaque rupture in diabetic patients with ACS is unclear. Intravascular ultrasound (IVUS) can provide detailed, high-quality tomographic images to detect plaque rupture in vivo [13]. In the present study, we investigated whether any relation exists between serum 1,5-AG level and ruptured plaque in culprit lesion identified by IVUS in diabetic patients with ACS.

\section{Methods}

\section{Patient population and study design}

This is a prospective observational study. We included 220 type 2 diabetes mellitus (T2DM) patients with ACS, who were admitted to Shanghai General Hospital Baoshan Branch and Beijing Anzhen Hospital between December 2018 and July 2019. All enrolled patients were admitted and underwent coronary angiography and IVUS in the culprit vessel. Patients with any of the following were excluded from the study: (1) totally occlusive lesions, (2) restenosis after stenting, (3) previous coronary artery bypass graft surgery, (4) severe heart failure (NYHA functional class III or above), renal failure (creatinine clearance $<30 \mathrm{~mL} / \mathrm{min}$ ), hepatic insufficiency, or infectious disease, (5) $\mathrm{HbA}_{1 \mathrm{c}}>8 \%$, (6) taking sodium-glucose cotransporter 2 inhibitor, and (7) insufficient clinical data. A total of 144 patients were included for analysis after excluding 76 patients who meeting the exclusion criteria. 49 patients had coronary plaque rupture in culprit lesion diagnosed by IVUS. ACS consisted of ST-segment elevation myocardial infarction (STEMI), non-ST-segment elevation myocardial infarction (NSTEMI) and unstable angina pectoris, which were defined according to 2013 ACCF/AHA guideline for the management of STEMI and 2014 ACC/AHA guideline for NSTE-ACS. T2DM was diagnosed according to the American Diabetes Association criteria or medical history and the use of insulin or glucose-lowering medication. Hypertension was defined as systolic blood pressure $\geq 140 \mathrm{mmHg}$ and/or diastolic blood pressure $\geq 90 \mathrm{mmHg}$ or treatment with oral antihypertensive drugs. Hyperlipidemia was diagnosed according to the modified National Cholesterol Education Program-Adult Treatment Panel III. The study protocol was approved beforehand by the Medical Ethics Committee of Shanghai General Hospital Baoshan Branch and the Medical Ethics Committee of Beijing Anzhen Hospital, and the procedures followed were in accordance with the institutional guidelines. The study complied with the Declaration of Helsinki, and informed consent was obtained from all patients.

\section{IVUS imaging protocol and analysis}

All patients were performed with coronary angiography by standard Judkins technique. IVUS examination was performed using an IVUS system (iLAB ${ }^{\mathrm{TM}}$ Ultrasound Imaging System, Boston Scientific, USA) and a $40 \mathrm{MHz}$ intravascular catheter (OptiCross ${ }^{\mathrm{TM}}$, Boston Scientific, USA) before any intervention. The IVUS catheter was advanced into the culprit vessel more than $10 \mathrm{~mm}$ beyond the culprit lesion and withdrawn at a pullback speed of $0.5 \mathrm{~mm} / \mathrm{s}$ automatically. In this study, a culprit lesion was defined as the lesion related to the clinical event, as identified by both coronary angiography and electrocardiogram findings. A ruptured plaque was defined as the plaque contained a cavity that communicated with the lumen with an overlying residual fibrous cap fragment. A fragmented and loosely adherent plaque without a distinct cavity and without a fibrous cap fragment was not considered as a plaque rupture [14]. IVUS quantitative analysis was performed by two independent experienced interventional cardiologists who were blinded to the patients' clinical information according to the criteria of the American College of Cardiology Clinical Expert Consensus Document on IVUS.

\section{Laboratory measurement}

We collected blood samples and urine samples from patients after overnight fasting. Samples were stored at $-80{ }^{\circ} \mathrm{C}$ prior to analysis. Serum levels of 1,5 -AG were measured by a colorimetric method (Nippon Kayaku, Tokyo, Japan) using a Lana 1,5-AG auto liquid automatic analyzer (JCA-BM 8060, JEOL Ltd., Tokyo, Japan). Serum concentration of hemoglobin $\mathrm{A}_{1 \mathrm{c}}\left(\mathrm{HbA}_{1 \mathrm{c}}\right)$ was determined by high-performance liquid chromatographic method (Tosoh HLC-723G7; Tosoh Corporation, Tokyo, Japan). The urinary 8-iso-prostaglandin $\mathrm{F}_{2 \alpha}$ (8-iso- $\mathrm{PGF}_{2 \alpha}$ ) 
levels were measured by a competitive enzyme-linked immunosorbent assay (Cayman Chemical, Ann Arbor, MI, USA) and corrected by creatinine clearance. The plasma concentration of fasting blood glucose (FBG), creatinine, total cholesterol (TC), high-density lipoprotein cholesterol (HDL-c), low-density lipoprotein cholesterol (LDL-c), triglyceride (TG), the high-sensitivity C-reactive protein (hs-CRP), N-terminal pro-brain natriuretic peptide (NT-proBNP), and troponin I (TnI) were measured. The non-HDL-c level was calculated as the TC level minus the HDL-c level.

\section{Statistical analysis}

All statistical analyses were performed by using SPSS for Windows 24.0 (SPSS Inc, Chicago, IL, USA). All data were tested for normal distribution with the Kolmogorov-Smirnov test. Data are presented as mean with standard deviation (SD) for continuous distributed variables, frequencies and percentages for categorical variables, and median with $25 \%$ and $75 \%$ percentiles for abnormal distributed parameters. Differences between two groups were assessed by using the t-tests, Chi square, and Mann-Whitney rank analysis. Correlation between continuous variables was determined by Pearson correlation coefficients. Univariate and multivariate logistic regression analyses were performed in tow models to identify independent predictors for ruptured culprit plaque in study population. 1,5-AG level was included as a continuous variable in Model 1 and as a categorized variable (categorized into tertiles) in Model 2. The predictive value of $1,5-\mathrm{AG}$ and $\mathrm{HbA}_{1 \mathrm{c}}$ for the presence of ruptured plaque in culprit lesion was calculated by constructing receiver-operating characteristic (ROC) curves. A value of $\mathrm{P}<0.05$ was considered statistically significant.

\section{Results \\ Clinical characteristics of patients}

During the study period, 220 diabetic patients with ACS underwent CAG and IVUS. We excluded 16 patients with restenosis after stenting, 15 patients with insufficient IVUS data, 5 patients with severe heart failure, 8 patients with renal failure, 14 patients without 1,5-AG data, and 18 patients with other data loss. Finally, a total of 144 patients were enrolled into the present study. Among of all subjects, 49 patients had culprit plaque rupture detected by IVUS (Rupture group), 95 patients had not (Non-rupture group) (Fig. 1). Compared to patients of non-rupture group, those patients with ruptured plaque had significantly lower 1,5 -AG levels $(10.5 \pm 5.5$ vs. $14.1 \pm 7.7 \mu \mathrm{g} / \mathrm{mL}, \mathrm{P}=0.005)$, longer duration of diabetes [median (interquartile range): $4.2(2.0,5.2)$ vs. 2.5 (1.2, 4.8) years, $\mathrm{P}=0.009$ ], higher FBG $(8.1 \pm 3.0$ vs. $7.1 \pm 2.0 \mathrm{mmol} / \mathrm{L}, \mathrm{P}=0.023), \mathrm{HbA}_{1 \mathrm{c}}(7.2 \pm 0.5$ vs. $7.0 \pm 0.6 \%, \mathrm{P}=0.025)$, and non-HDL-c $[4.39(3.63,4.99)$ vs. $3.83(3.43,4.36) \mathrm{mmol} / \mathrm{L}, \mathrm{P}=0.006$ ] levels. Patients with plaque rupture also had higher hs-CRP [2.46 (1.61,

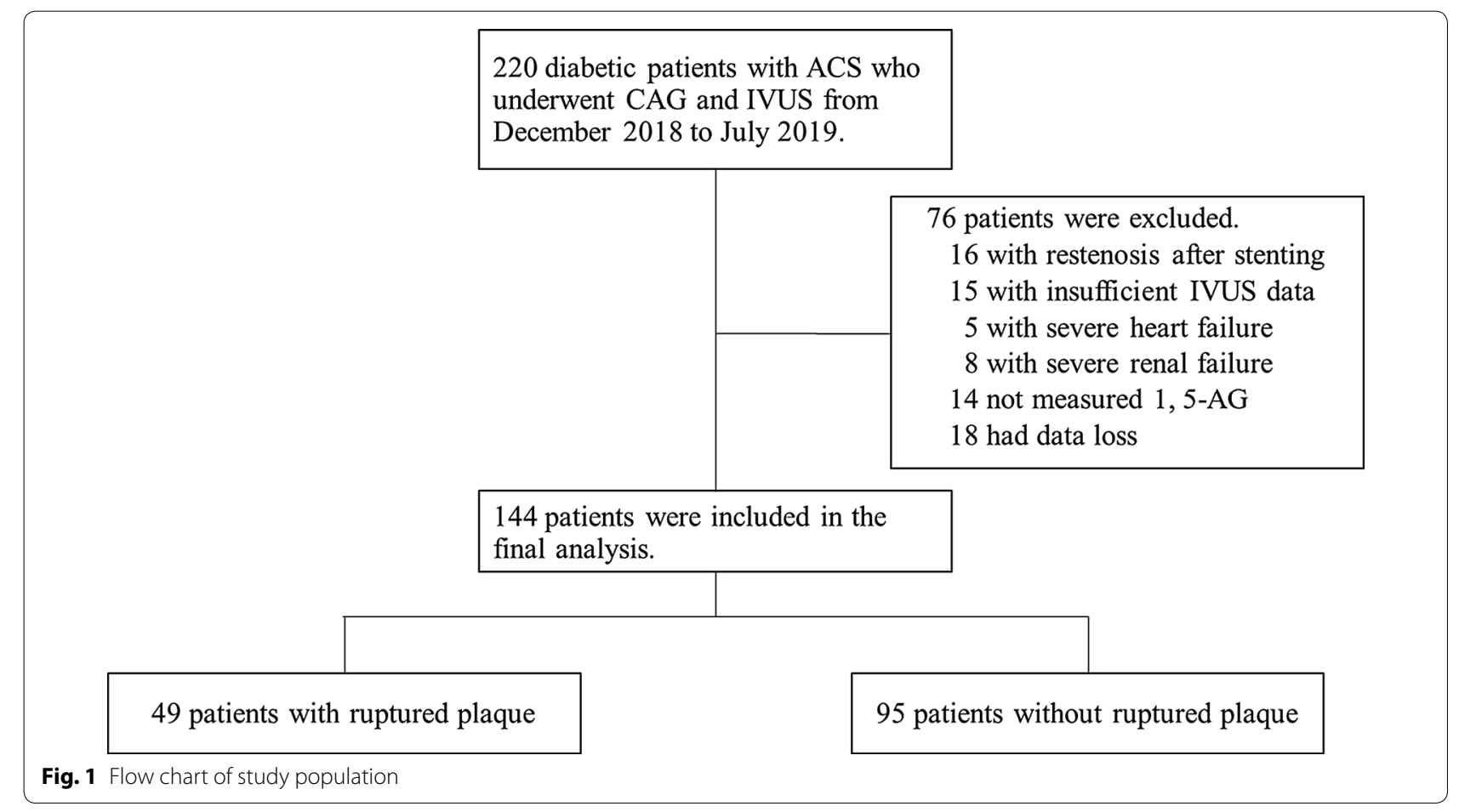


5.23) vs. $1.22(0.84,4.01), \mathrm{P}=0.014]$ and urinary 8-iso$\mathrm{PGF}_{2 \alpha}(141.9 \pm 67.2$ vs. $116.1 \pm 71.6 \mathrm{pmol} / \mathrm{mmolCr}$, $\mathrm{P}=0.038$ ) levels than patients without plaque rupture. No significant differences were observed between two groups in terms of age, gender, hypertension, hyperlipidemia, body mass index (BMI), blood pressure, eGFR, and medicine treatments (Table 1 ).

\section{Angiographic and IVUS results}

Angiographic findings and IVUS analysis were summarized in Table 2. Culprit lesions of all 144 enrolled patients were evaluated by IVUS. Plaque rupture was observed in 49 patients (34\%). There were no significant differences in culprit lesion location and three-vessel disease between plaque rupture and non-rupture groups. IVUS data showed there were not significant differences in lesion volume, length, plaque burden, external elastic membrane cross-sectional areas, lumen cross-sectional areas, plaque plus media cross-sectional areas, and remodeling index between patients with and without plaque rupture.

\section{Relationship between 1,5-AG level and plaque rupture}

We performed univariate and multivariate analysis to determine independent predictors for plaque rupture in culprit lesion. For multivariable regression analysis in model 1, variables (age, gender, current smoking, duration of diabetes, body mass index (BMI), left ventricular

Table 1 Clinical characteristics in the study population

\begin{tabular}{|c|c|c|c|}
\hline Variables & Rupture & Non-rupture & $P$ value \\
\hline$n$ & 49 & 95 & \\
\hline Age (years) & $59 \pm 9$ & $60 \pm 10$ & 0.474 \\
\hline Males & $28(57.1)$ & $62(65.3)$ & 0.340 \\
\hline Current smoking & $34(69.4)$ & $51(53.7)$ & 0.069 \\
\hline Hypertension & $36(73.5)$ & $65(68.4)$ & 0.531 \\
\hline Hyperlipidemia & $32(65.3)$ & $58(61.1)$ & 0.617 \\
\hline Duration of diabetes (years) & $4.2(2.0,5.2)$ & $2.5(1.2,4.8)$ & 0.009 \\
\hline BMI $\left(\mathrm{kg} / \mathrm{m}^{2}\right)$ & $26.4 \pm 3.6$ & $25.6 \pm 3.5$ & 0.110 \\
\hline $\operatorname{LVEF}(\%)$ & $59.5 \pm 8.3$ & $62.2 \pm 9.2$ & 0.092 \\
\hline eGFR $\left(\mathrm{mL} / \mathrm{min} / 1.73 \mathrm{~m}^{2}\right)$ & $84.6 \pm 28.6$ & $88.0 \pm 30.8$ & 0.491 \\
\hline $\mathrm{SBP}(\mathrm{mmHg})$ & $130 \pm 13$ & $131 \pm 16$ & 0.612 \\
\hline $\mathrm{DBP}(\mathrm{mmHg})$ & $76 \pm 8$ & $77 \pm 10$ & 0.638 \\
\hline TG (mmol/L) & $1.93(1.12,2.13)$ & $1.72(0.94,1.88)$ & 0.079 \\
\hline $\mathrm{HDL}-\mathrm{C}(\mathrm{mmol} / \mathrm{L})$ & $0.96(0.82,1.24)$ & $1.02(0.91,1.23)$ & 0.314 \\
\hline Non-HDL-C (mmol/L) & $4.39(3.63,4.99)$ & $3.83(3.43,4.36)$ & 0.006 \\
\hline $\operatorname{WBC}\left(10^{9} / \mathrm{L}\right)$ & $7.3 \pm 1.6$ & $7.2 \pm 1.7$ & 0.958 \\
\hline hs-CRP (mg/dL) & $2.46(1.61,5.23)$ & $1.22(0.84,4.01)$ & 0.014 \\
\hline NT-proBNP & $390(155,960)$ & $362(105,890)$ & 0.413 \\
\hline Tnl & $1.20(0.11,5.12)$ & $0.91(0.03,2.62)$ & 0.228 \\
\hline Urinary 8-iso-PGF $2 a(p m o l / m m o l c r)$ & $141.9 \pm 67.2$ & $116.1 \pm 71.6$ & 0.038 \\
\hline FBG $(\mathrm{mmol} / \mathrm{L})$ & $8.1 \pm 3.0$ & $7.1 \pm 2.0$ & 0.023 \\
\hline $\mathrm{HbA}_{1 \mathrm{c}}(\%)$ & $7.2 \pm 0.5$ & $7.0 \pm 0.6$ & 0.025 \\
\hline 1,5-AG ( $\mu \mathrm{g} / \mathrm{mL})$ & $10.5 \pm 5.5$ & $14.1 \pm 7.7$ & 0.005 \\
\hline \multicolumn{4}{|l|}{ Medications on admission } \\
\hline Aspirin & $36(73.5)$ & $71(74.7)$ & 0.869 \\
\hline Statins & $27(55.1)$ & $62(65.3)$ & 0.234 \\
\hline ACEI/ARB & $25(51.0)$ & $52(54.7)$ & 0.672 \\
\hline Oral antidiabetic drugs & $31(63.3)$ & $64(67.4)$ & 0.622 \\
\hline Insulin & $16(32.7)$ & $32(33.7)$ & 0.901 \\
\hline
\end{tabular}

Data are given as number (percentage) for categorical variables and mean \pm standard deviation or median (IQR) for continuous variables

$B M I$ body mass index, LVEF left ventricular ejection fraction, eGFR estimated glomerular filtration rate, SBP systolic blood pressure, DBP diastolic blood pressure, TG triglycerides, $H D L-C$ high-density lipoprotein cholesterol, non-HDL-C non-high-density lipoprotein cholesterol, WBC white blood cell, hs-CRP high-sensitivity C-reactive protein, NT-proBNP N-terminal pro-brain natriuretic peptide, Tn/ troponin I, 8-iso- $P G F_{2 a}$ 8-iso-prostaglandin $\mathrm{F}_{2 a^{\prime}} F B G$ fasting blood glucose, $H b A_{1 c}$ hemoglobin $\mathrm{A}_{1 c^{\prime}} 1,5$ $A G$ 1,5-anhydroglucitol, $A C E I / A R B$ angiotensin-converting-enzyme inhibitor/angiotensin II receptor blocker 


\begin{tabular}{|c|c|c|c|}
\hline Variables & Rupture & Non-rupture & $P$ value \\
\hline$n$ & 49 & 95 & \\
\hline \multicolumn{4}{|l|}{ Angiographic analysis } \\
\hline Culprit lesion & & & 0.694 \\
\hline LM & $2(2.6)$ & $5(5.3)$ & \\
\hline LAD & $20(34.2)$ & $38(40.4)$ & \\
\hline LCX & $9(15.8)$ & $16(16.0)$ & \\
\hline $\mathrm{RCA}$ & $18(47.4)$ & $36(38.3)$ & \\
\hline Lesion location & & & 0.579 \\
\hline Ostial & $2(2.6)$ & $6(6.4)$ & \\
\hline Proximal & $18(34.2)$ & $33(35.1)$ & \\
\hline Mild & $23(52.6)$ & $44(46.8)$ & \\
\hline Distal & $6(10.5)$ & $12(11.7)$ & \\
\hline 3-vessel disease & $21(42.9)$ & $33(34.7)$ & 0.340 \\
\hline \multicolumn{4}{|l|}{ IVUS analysis } \\
\hline EEM CSA $\left(\mathrm{mm}^{2}\right)$ & $20.9 \pm 6.4$ & $19.4 \pm 5.4$ & 0.106 \\
\hline Lumen CSA $\left(\mathrm{mm}^{2}\right)$ & $4.3 \pm 1.4$ & $4.2 \pm 1.0$ & 0.585 \\
\hline $\mathrm{P} \& \mathrm{M}$ CSA $\left(\mathrm{mm}^{2}\right)$ & $16.6 \pm 5.9$ & $15.1 \pm 5.4$ & 0.164 \\
\hline Plaque burden (\%) & $78.6 \pm 8.0$ & $76.8 \pm 8.3$ & 0.209 \\
\hline Length $(\mathrm{mm})$ & $19.0 \pm 5.4$ & $18.6 \pm 6.8$ & 0.688 \\
\hline Volume $\left(\mathrm{mm}^{3}\right)$ & $135.7 \pm 55.3$ & $127.4 \pm 58.5$ & 0.402 \\
\hline Remodeling index & $1.01 \pm 0.15$ & $0.97 \pm 0.17$ & 0.196 \\
\hline
\end{tabular}

Data are given as number (percentage) for categorical variables and mean \pm standard deviation

$L M$ left main coronary artery, $L A D$ left anterior descending coronary artery, $L C X$ left circumflex coronary artery, RCA right coronary artery, IVUS intravascular ultrasound, EEM external elastic membrane, CSA cross-sectional areas, $P \& M$ plaque plus media

ejection fraction (LVEF), TG, non-HDL-C, hs-CRP, urinary 8-iso-PGF ${ }_{2 \alpha}, 1,5$-AG, FBG and $\mathrm{HbA}_{1 \mathrm{c}}$ ] were entered into the univariate regression analysis, and variables with $\mathrm{P}<0.10$ (current smoking, duration of diabetes, LVEF, TG, non-HDL-C, urinary 8-iso-PGF ${ }_{2 \alpha}, 1,5-\mathrm{AG}, \mathrm{FBG}$ and $\left.\mathrm{HbA}_{1 \mathrm{c}}\right)$ and forced inclusion variables that were considered as important predictors of plaque rupture or associated with 1,5-AG (age, gender, BMI) were further entered into the multivariable regression model. The result showed that 1,5-AG (OR 0.916, 95\% CI 0.852-0.985, $\mathrm{P}=0.018$ ) as well as other variables (current smoking and non-HDL-C) were associated with risk of culprit plaque rupture (Table 3 ). In model 2 , age ( $\geq 65$ years), duration of diabetes (upper tertile, $\geq 4.8$ years), BMI ( $>30 \mathrm{~kg} /$ $\left.\mathrm{m}^{2}\right)$, LVEF $(<40 \%)$, TG $(>1.70 \mathrm{mmol} / \mathrm{L})$, non-HDL-C $(\geq 4.1 \mathrm{mmol} / \mathrm{L})$, hs-CRP ( $>3 \mathrm{mg} / \mathrm{L}), 1,5$-AG (lower tertile, $<9.78 \mu \mathrm{g} / \mathrm{mL})$, FBG $(\geq 7.0 \mathrm{mmol} / \mathrm{L}), \mathrm{HbA}_{1 \mathrm{c}}(>7 \%)$ and urinary 8 -iso- PGF $_{2 \alpha}$ (upper tertile, $>140 \mathrm{pmol} /$ $\mathrm{mmolCr}$ ) were included as categorized variables. Low level of 1,5-AG (OR 3.421, 95\% CI 1.446-8.092, $\mathrm{P}=0.005$ ), current smoking (OR 3.529, 95\% CI 1.2929.638, $\mathrm{P}=0.014)$, high level of non-HDL-c (OR 4.857,
95\% CI 1.871-12.61, $\mathrm{P}=0.001)$ and $\mathrm{HbA}_{1 \mathrm{c}}(\mathrm{OR} 2.458$, $95 \% \mathrm{CI} 1.081-5.586, \mathrm{P}=0.032)$ were significantly associated with culprit plaque rupture in diabetic patients with ACS (Table 3). We constructed a ROC curve for predicting ruptured culprit plaque by $1,5-\mathrm{AG}$ and $\mathrm{HbA}_{1 \mathrm{c}}$ levels in patients. The area under the ROC curve for reciprocal of 1,5-AG $(0.658,95 \%$ CI $0.563-0.752, \mathrm{P}=0.002)$ was significantly superior to that for $\mathrm{HbA}_{1 \mathrm{c}}(0.587,95 \% \mathrm{CI}$ $0.490-0.684, \mathrm{P}=0.087$ ) (Fig. 2). The optimal cut-off value for 1,5-AG to predict culprit plaque rupture was $11.8 \mu \mathrm{g} /$ $\mathrm{mL}(69.4 \%$ sensitivity and $59.8 \%$ specificity).

\section{Correlation between serum 1,5-AG level and urinary 8-iso-PGF $2 a^{\prime}$ or other ACS biomarkers}

A significant negative correlation was noted between serum level of 1,5-AG and urinary 8-iso- PGF $_{2 \alpha}$ level $(\mathrm{r}=-0.234, \mathrm{P}=0.005)$ (Fig. 3). There was no significant correlation between the level of 1,5-AG and hs-CRP $(r=-0.116, P=0.165)$, TnI $(r=-0.012, P=0.887)$, or NT-proBNP $(\mathrm{r}=-0.011, \mathrm{P}=0.898)$. The correlation between $\mathrm{HbA}_{1 \mathrm{c}}$ level and urinary 8 -iso-PGF $\mathrm{PG}_{2 \alpha}$ level was also not significant $(r=0.076, \mathrm{P}=0.368)$.

\section{Discussion}

Most cases of sudden cardiac death and myocardial infarction arise from thrombotic coronary occlusion following coronary plaque rupture. Diabetic patients had more plaque ruptures and thrombus than non-diabetic patients in ACS, which may be associated with the greater rates of cardiovascular events in diabetes [15]. However, available screening and diagnostic methods are insufficient to identify the victims before the event occurs. The search for noninvasive approach to detect the plaque rupture was encouraged to perform. In our present study, the principal result shows that serum 1,5AG, as a biomarker of short-term postprandial hyperglycemia and GV, might be an important surrogate marker of coronary plaque rupture in diabetic patients with ACS.

\section{1,5-AG levels and coronary plaque rupture}

1,5-AG is a naturally occurring 1-deoxy form of glucose. As glucose levels surpass the renal threshold for glucosuria (generally around $10 \mathrm{mmol} / \mathrm{L}$ ), 1,5-AG is excreted in the urine leading to a rapid reduction in serum levels [16]. Therefore, poor glycemic control is associated with low, rather than high, serum 1,5-AG levels. Unlike $\mathrm{HbA}_{1 \mathrm{c}}, 1,5-\mathrm{AG}$ values are not affected by mean erythrocyte age and can accurately reflect the glycemic control in hemolytic patients [17]. On the other hand, 1,5-AG levels can also reflect the status of gestational DM in pregnant women and may anticipate the development of gestational DM [18]. In the present study, we used IVUS to identify plaque rupture 
Table 3 Independent predictors for ruptured culprit plaque

\begin{tabular}{|c|c|c|c|c|c|c|c|c|c|}
\hline \multirow[t]{2}{*}{ Model 1} & \multicolumn{2}{|l|}{ Univariate } & \multicolumn{2}{|l|}{ Multivariate } & \multirow[t]{2}{*}{ Model 2} & \multicolumn{2}{|l|}{ Univariate } & \multicolumn{2}{|l|}{ Multivariate } \\
\hline & OR $(95 \% \mathrm{Cl})$ & $P$ value & OR $(95 \% \mathrm{Cl})$ & $P$ value & & OR $(95 \% \mathrm{Cl})$ & $P$ value & OR $(95 \% \mathrm{Cl})$ & $P$ value \\
\hline Age & $\begin{array}{l}0.992(0.958 \\
1.028)\end{array}$ & 0.672 & & & Age ( $\geq 65$ years) & $\begin{array}{l}0.869(0.414 \\
1.824)\end{array}$ & 0.710 & & \\
\hline Female & $\begin{array}{l}1.305(0.608 \\
2.801)\end{array}$ & 0.494 & & & Female & $\begin{array}{l}1.305(0.608 \\
2.801)\end{array}$ & 0.494 & & \\
\hline Current smoking & $\begin{array}{l}2.278(0.961 \\
5.398)\end{array}$ & 0.062 & $\begin{array}{l}2.647(1.018 \\
6.883)\end{array}$ & 0.046 & Current smoking & $\begin{array}{l}2.278(0.961 \\
5.398)\end{array}$ & 0.062 & $\begin{array}{l}3.529(1.292 \\
9.638)\end{array}$ & 0.014 \\
\hline $\begin{array}{l}\text { Duration of } \\
\text { diabetes }\end{array}$ & $\begin{array}{l}1.059(0.991 \\
1.130)\end{array}$ & 0.090 & & & $\begin{array}{l}\text { Duration of diabe- } \\
\text { tes (Upper ter- } \\
\text { tile, } \geq 4.8 \text { years) }\end{array}$ & $\begin{array}{l}1.773(0.851 \\
3.695)\end{array}$ & 0.126 & & \\
\hline Body mass index & $\begin{array}{l}1.102(0.978 \\
1.243)\end{array}$ & 0.111 & & & $\begin{array}{l}\text { Body mass index } \\
\left(>30 \mathrm{~kg} / \mathrm{m}^{2}\right)\end{array}$ & $\begin{array}{l}1.956(0.943 \\
4.055)\end{array}$ & 0.071 & & \\
\hline LVEF & $\begin{array}{l}0.968(0.932, \\
1.006)\end{array}$ & 0.095 & & & $\operatorname{LVEF}(<40 \%)$ & $\begin{array}{l}1.718(0.659 \\
4.479)\end{array}$ & 0.268 & & \\
\hline TG & $\begin{array}{l}1.353(0.961 \\
1.906)\end{array}$ & 0.084 & & & $\mathrm{TG}(>1.70 \mathrm{mmol} / \mathrm{L})$ & $\begin{array}{l}1.681(0.810 \\
3.490)\end{array}$ & 0.164 & & \\
\hline Non-HDL-C & $\begin{array}{l}1.904(1.233 \\
2.940)\end{array}$ & 0.004 & $\begin{array}{l}1.983(1.236 \\
3.183)\end{array}$ & 0.005 & $\begin{array}{l}\text { non-HDL-C } \\
\quad(\geq 4.1 \mathrm{mmol} / \mathrm{L})\end{array}$ & $\begin{array}{l}4.016(1.736 \\
9.293)\end{array}$ & 0.001 & $\begin{array}{l}4.857(1.871 \\
12.61)\end{array}$ & 0.001 \\
\hline hs-CRP & $\begin{array}{l}1.007(0.940 \\
1.080)\end{array}$ & 0.837 & & & hs-CRP (>3 mg/L) & $\begin{array}{l}1.372(0.668 \\
2.817)\end{array}$ & 0.389 & & \\
\hline $1,5-A G$ & $\begin{array}{l}0.914(0.856 \\
0.976)\end{array}$ & 0.007 & $\begin{array}{l}0.916(0.852 \\
0.985)\end{array}$ & 0.018 & $\begin{array}{l}\text { 1, 5-AG (Lower } \\
\text { tertile, <9.78 } \mu \mathrm{g} / \\
\mathrm{mL})\end{array}$ & $\begin{array}{l}3.631(1.752 \\
7.524)\end{array}$ & 0.001 & $\begin{array}{l}3.421(1.446 \\
8.092)\end{array}$ & 0.005 \\
\hline FBG & $\begin{array}{l}1.176(1.019 \\
1.357)\end{array}$ & 0.026 & & & $\begin{array}{l}\mathrm{FBG} \\
\qquad(\geq 7.0 \mathrm{mmol} / \mathrm{L})\end{array}$ & $\begin{array}{l}1.367(0.685 \\
2.729)\end{array}$ & 0.375 & & \\
\hline $\mathrm{HbA}_{1 \mathrm{c}}$ & $\begin{array}{l}1.989(1.083 \\
3.653)\end{array}$ & 0.027 & & & $\mathrm{HbA}_{1 \mathrm{c}}(>7 \%)$ & $\begin{array}{l}1.996(0.984 \\
4.048)\end{array}$ & 0.055 & $\begin{array}{l}2.458(1.081 \\
5.586)\end{array}$ & 0.032 \\
\hline $\begin{array}{l}\text { Urinary 8-iso- } \\
\text { PGF }_{2 a}\end{array}$ & $\begin{array}{l}1.005(1.000 \\
1.010)\end{array}$ & 0.042 & & & $\begin{array}{l}\text { Urinary 8-iso- } \\
\text { PGF }_{2 a} \\
\text { (Upper ter- } \\
\text { tile, >140 pmol/ } \\
\text { mmolCr) }\end{array}$ & $\begin{array}{l}2.493(1.222 \\
5.085)\end{array}$ & 0.012 & & \\
\hline
\end{tabular}

Model 1: Age, duration of diabetes, body mass index, LVEF, TG, non-HDL-C, hs-CRP, 1,5-AG, FBG, $\mathrm{HbA}_{1 \mathrm{c}}$ and urinary 8 -iso-PGF $2 a$ were included as continuous variables. Model 2: All variables were included as categorized variables

LVEF left ventricular ejection fraction, $T G$ triglycerides, non-HDL-C non-high-density lipoprotein cholesterol, $h s$ - $C R P$ high-sensitivity $C$-reactive protein, 1,5- $A G$ 1,5-anhydroglucitol, $F B G$ fasting blood glucose, $H b A_{1 c}$ hemoglobin $\mathrm{A}_{1 c^{\prime}}$ 8-iso- $P G F_{2 a}$ 8-iso-prostaglandin $\mathrm{F}_{2 a}$

in culprit lesion of diabetic patients with ACS and found that the 1,5-AG levels were significantly lower in patients with ruptured plaque than in patients without ruptured plaque. Meanwhile, patients with ruptured plaque had higher $\mathrm{HbA}_{1 \mathrm{c}}$, FBG, and non-HDL-c levels compared to patients with non-ruptured plaque. This result indicates that diabetic patients with ruptured culprit plaque had worse glycometabolic and lipidemic disorders. In accordance with some recent in vivo studies $[19,20]$, no differences were observed for age and sex between the patients with or without culprit plaque rupture. In model 1 and model 2, univariate and multivariate logistic regression analyses showed that low 1,5-AG, high non-HDL-c levels and current smoking were independent predictors of plaque rupture of culprit lesion in diabetic patients with ACS. These results indicate that poor glycemic control and dyslipidemia may be associated with the coronary plaque rupture in diabetes. Sheng et al. reported that increased duration of DM combined with higher $\mathrm{HbA}_{1 \mathrm{c}}$ levels influences culprit-plaque characteristics in patients with DM who suffer AMI [21]. In the present study, patients with ruptured plaque had longer duration of DM and higher $\mathrm{HbA}_{1 \mathrm{c}}$ levels than patients without ruptured plaque. The level of $\mathrm{HbA}_{1 \mathrm{c}}>7 \%$ is associated with an increased risk of culprit plaque rupture. Moreover, the ROC curve analysis showed 1,5-AG displayed more significant value in predicting plaque rupture than $\mathrm{HbA}_{1 \mathrm{c}}$. Preliminary data have shown that 1,5-AG could be expected to best reflect postprandial hyperglycemia in moderately controlled patients and was more sensitive and specific than $\mathrm{HbA}_{1 \mathrm{c}}$ [22]. Furthermore, as PPG increments are the major contributors to GV in T2DM, 1,5-AG may be particularly suited for monitoring 


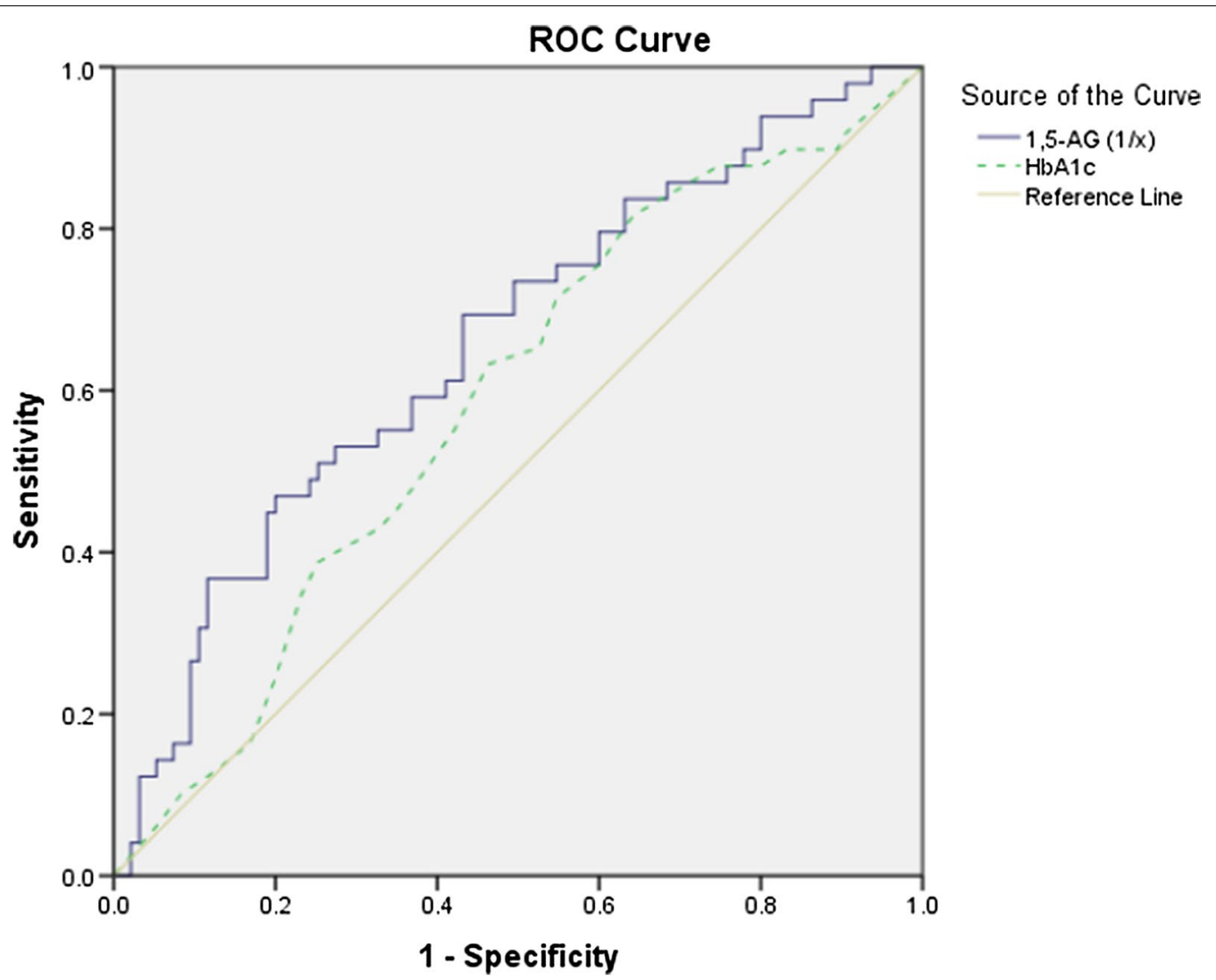

Fig. 2 Receiver-operating characteristic curves of 1,5-AG and $\mathrm{HbA}_{1 c}$ levels to predict coronary plaque rupture in diabetic patients with $\mathrm{ACS}$. The areas under the curve of 1,5- $\mathrm{AG}(1 / \mathrm{X})$ and $\mathrm{HbA}_{1 \mathrm{c}}$ levels were $0.658(0.563-0.752, \mathrm{P}=0.002)$ and $0.587(0.490-0.684, \mathrm{P}=0.087)$, respectively. 1,5-AG 1,5-anhydro-D-glucitol, $H b A_{1 c}$ hemoglobin $A_{1 c}$

postprandial hyperglycemic excursions [23]. Unlike $\mathrm{HbA}_{1 \mathrm{c}}, 1,5-\mathrm{AG}$ is not affected by hypoglycemia. As a result, 1,5-AG appears to differentiate patients with extensive PPG excursions despite having similar $\mathrm{HbA}_{1 \mathrm{c}}$ levels. Selvin et al. reported that patients with low 1,5-AG levels had an increased risk of coronary artery disease, stroke, heart failure, and death compared to patients with high 1,5-AG levels [10]. Takahashi et al. reported that low and exacerbated levels of 1,5-AG are associated with cardiac mortality in ACS patients [11]. The study of Fujiwara et al. showed that 1,5-AG was associated with the presence of de novo coronary artery disease in both well-controlled diabetic and non-diabetic patients [8]. Low 1,5-AG level had been found to be associated with coronary artery calcification, which may be related to the coronary plaque vulnerability [24, 25 ]. The current study is the first to report that 1,5-AG levels are significantly associated with coronary plaque rupture in diabetic patients with ACS. These findings may partly explain the results of previous studies that 1,5-AG levels were associated with cardiovascular outcomes and support the hypothesis that PPG excursions is strongly associated with the atherosclerotic vulnerable plaque process.

\section{Mechanism for PPG excursions affecting plaque rupture}

Although the identified role of PPG excursions in the pathogenesis of plaque rupture has not been clarified, oxidative stress, inflammation and endothelial dysfunction may be involved in the process. It was demonstrated that glucose excursions increased oxidative stress than chronic hyperglycemia in T2DM. Ceriello et al. showed that targeting postprandial hyperglycemia has the potential to reduce oxidative stress [26]. We have recently reported that glycemic variability, a component of which is PPG excursions, was significantly correlated with oxidative stress measured as urinary 8 -iso-PGF ${ }_{2 \alpha}$ in patients with ACS [27]. Urinary 8-iso- $\mathrm{PGF}_{2 \alpha}$ have been proved to be the most reliable marker to assess lipid peroxidation, which is a key mechanism for the development of atherosclerotic plaques in humans. The present study showed that serum 1,5-AG level, but not $\mathrm{HbA}_{1 \mathrm{c}}$, was strongly correlated with urinary 8-iso- $\mathrm{PGF}_{2 \alpha}$ level in diabetic patients with ACS. This is in accordance with the 


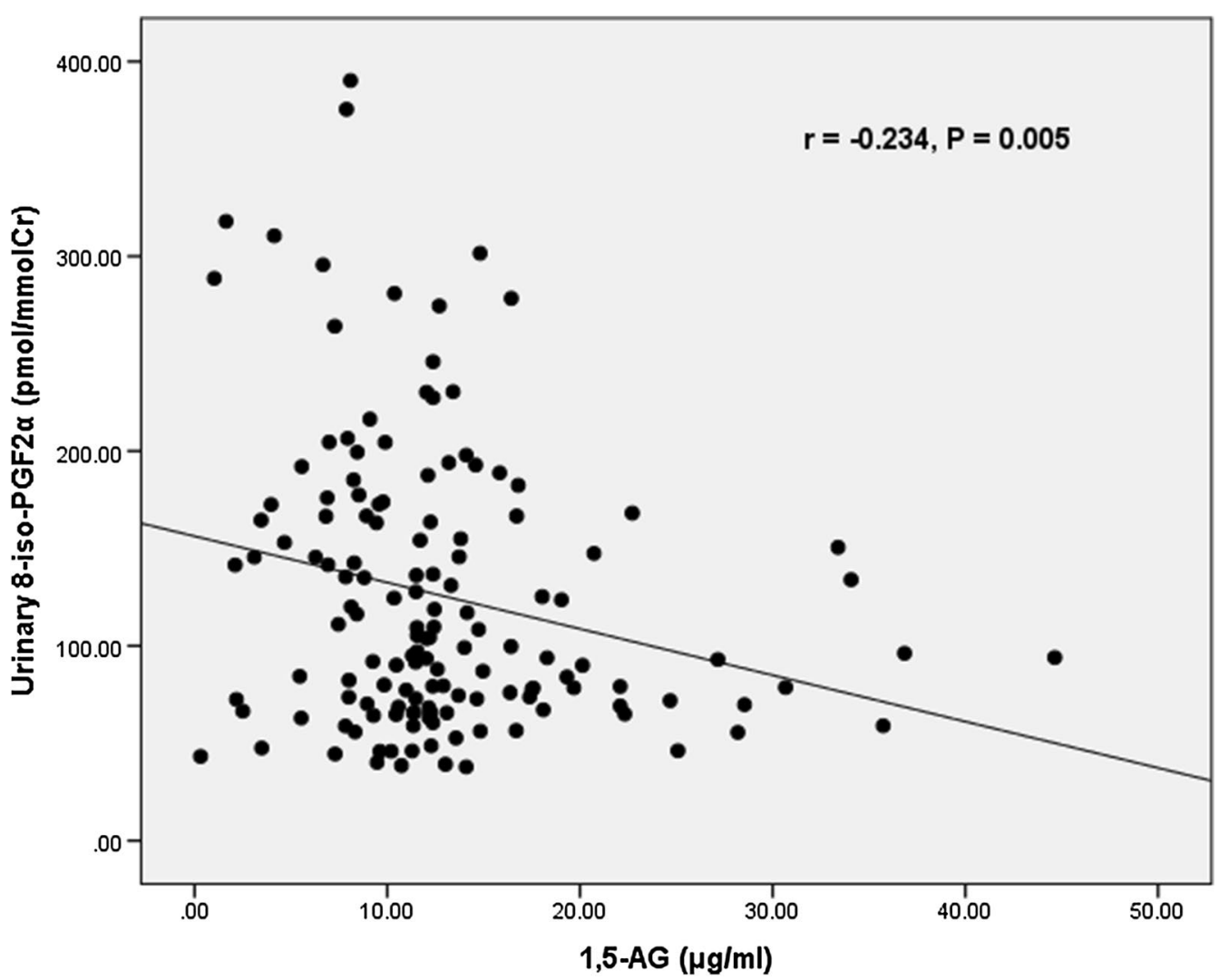

Fig. 3 Correlations between serum 1,5-AG level and urinary 8-iso-PGF 2 level in diabetic patients with acute coronary syndrome. 1,5-AG 1,5-anhydro-D-glucitol, 8-iso- $P G F_{2 a}$ 8-iso-prostaglandin $\mathrm{F}_{2 a}$

previous report of Kohata et al. that 1,5-AG is the strong correlate of oxidative stress in patients with T2DM [28], and it suggests that PPG excursions can be more important than mean glucose to induce oxidative stress in diabetes. It has been demonstrated that oxidative stress plays a key role in atherosclerotic plaque progression [29]. Our previous study showed that increased urinary 8 -iso- PGF $_{2 \alpha}$ levels were closely associated with greater absolute and percent necrotic core volumes of coronary lesions in diabetic patients [30]. In a pathological study by Nishibe et al., 8-iso- $\mathrm{PGF}_{2 \alpha}$ was found enriched in coronary plaque specimens especially from vulnerable patients, suggesting a crucial role of free radicals in the formation of vulnerable plaques [31]. Yura et al. reported that 8 -iso-PGF ${ }_{2 \alpha}$ per se could stimulate endothelin-1 mRNA and protein expression in bovine aortic endothelial cells [32]. Endothelin-1 may cause the stimulation of vascular smooth muscle proliferation and formation of macrophage-rich atherosclerotic plaques. In the study of Esposito et al., the results suggested that acute hyperglycemia, and not sustained elevation of blood glucose levels, could exaggerate inflammation by an oxidative mechanism [33]. Teraguchi et al. reported that dynamic glucose fluctuation was positively and significantly associated with $\mathrm{CD} 14^{\text {bright }} \mathrm{CD} 16+$ monocytes levels and might be related to coronary plaque rupture in patients with acute myocardial infarction [34]. All these findings suggest that postprandial hyperglycemic excursions may be involved in progression and destabilization of coronary plaques through the preferential increase in oxidative stress, proinflammatory cytokines, and endothelial dysfunction. Optimizing PPG excursions management may be helpful to prevent the rupture of coronary plaque in diabetic patients.

\section{Study limitations}

Several study limitations should be considered in the interpretation of the results. First, the sample size was relatively small, so that it may have influenced the results and the statistical analyses. Second, because we evaluated only limited patients who underwent IVUS and didn't meet any exclusion criteria, our results could have been affected by selection bias and cannot be generalized to all patients. Third, the assessment of plaque rupture was made by IVUS in this study. Although it has been demonstrated that IVUS can provide detailed, 
high-quality tomographic images to detect plaque rupture, it might be likely that some plaque ruptures were undetected. More detailed plaque morphology could be obtained by combining high definition IVUS with optical coherence tomography (OCT), virtually increasing accuracy for plaque rupture detection. Finally, this is an observational study. The observational nature of analysis means that we cannot infer causality in the associations we have demonstrated. Future longitudinal and prospective studies are needed to address these issues.

\section{Conclusions}

Serum 1,5-AG displayed significant value in predicting culprit plaque rupture in diabetic patients with ACS. This suggests that PPG excursions are related to the pathogenesis of plaque rupture in diabetes. The manipulation of PPG excursions may provide a potential therapeutic target for preventing plaque rupture.

\begin{abstract}
Abbreviations
1,5-AG: 1,5-Anhydroglucitol; PPG: Postprandial glucose; GV: Glycemic variability; ACS: Acute coronary syndrome; T2DM: Type 2 diabetes mellitus; IVUS: Intravascular ultrasound; 8-iso-PGF 2 : 8-Iso-prostaglandin $\mathrm{F}_{2 a^{\prime}}$ FBG: Fasting blood glucose; $\mathrm{HbA}_{1 \mathrm{c}}$ : Hemoglobin $\mathrm{A}_{1 \mathrm{c}}$; BMI: Body mass index; non-HDL-C: Non-high-density lipoprotein cholesterol; hs-CRP: High-sensitivity C-reactive protein; NT-proBNP: N-terminal pro-brain natriuretic peptide; Tnl: Troponin l; LVEF: Left ventricular ejection fraction.
\end{abstract}

\section{Acknowledgements}

We convey thanks to the professional technical assistance from the laboratory technicians at the Clinical Laboratory Center. The authors thank the volunteer patients for their participation, and the study nurses for their skills and devotion to the patient care.

\section{Authors' contributions}

GS and SWZ participated in the design of the study. GS and TZ participated in the exercise protocols. MXG, GLS and XXD performed laboratory measurement. WFY and TZ performed data collection. GS performed the statistical analysis and drafted the manuscript. SWZ participated in revising the manuscript. All authors read and approved the final manuscript.

\section{Funding}

This work was supported by a key grant from Outstanding Clinical Discipline Project of Shanghai Pudong (PWYgy 2018-05). This work was supported by a key grant from Beijing Health Special Foundation (JING 15-10). The funder was not involved in any study design, data collection and analysis, decision to publish, or preparation of the manuscript.

\section{Availability of data and materials}

The datasets used and/or analyzed during the current study are available from the corresponding author on reasonable request.

\section{Ethics approval and consent to participate}

The study was conducted in accordance with the Declaration of Helsinki, and was approved by the Medical Ethics Committee of Shanghai General Hospital Baoshan Branch and the Medical Ethics Committee of Beijing Anzhen Hospital. All participants provided written informed consent.

\section{Consent for publication}

Not applicable.

\section{Competing interests}

The authors of the manuscript do not have any closely related papers or manuscripts that have been submitted or published elsewhere and declare that they do not have any competing interests.

\section{Author details}

${ }^{1}$ Department of Cardiovascular Medicine, Shanghai General Hospital Baoshan Branch, No. 101 Tongtai North Road, Baoshan District, Shanghai 200940, China. ${ }^{2}$ Center of Cardiology, Beijing Anzhen Hospital, Capital Medical University, Beijing 100029, China. ${ }^{3}$ Department of Cardiovascular Medicine, The Seventh People's Hospital, Shanghai University of Traditional Chinese Medicine, No. 358 Gaoqiaodatong Road, Pudong District, Shanghai 200137, China.

Received: 10 March 2020 Accepted: 26 May 2020

Published online: 30 May 2020

\section{References}

1. Stefanadis C, Antoniou CK, Tsiachris D, Pietri P. Coronary atherosclerotic vulnerable plaque: current perspectives. J Am Heart Assoc. 2017;6(3):e005543.

2. Saia F, Komukai K, Capodanno D, Sirbu V, Musumeci G, Boccuzzi G, et al. Eroded versus ruptured plaques at the culprit site of stemi: in vivo pathophysiological features and response to primary PCI. JACC CardiovasC Imaging. 2015;8(5):566-75.

3. Higuma T, Soeda T, Abe N, Yamada M, Yokoyama H, Shibutani S, et al. A combined optical coherence tomography and intravascular ultrasound study on plaque rupture, plaque erosion, and calcified nodule in patients with st-segment elevation myocardial infarction: incidence, morphologic characteristics, and outcomes after percutaneous coronary intervention. JACC Cardiovasc Interv. 2015;8(9):1166-76.

4. Iannaccone M, Quadri G, Taha S, D'Ascenzo F, Montefusco A, Omede' $P$, et al. Prevalence and predictors of culprit plaque rupture at OCT in patients with coronary artery disease: a meta-analysis. Eur Heart J Cardiovasc Imaging. 2016;17(10):1128-37.

5. Virmani R, Kolodgie FD, Burke AP, Farb A, Schwartz SM. Lessons from sudden coronary death: a comprehensive morphological classification scheme for atherosclerotic lesions. Arterioscler Thromb Vasc Biol. 2000;20(5):1262-75.

6. Sugiyama T, Yamamoto E, Bryniarski K, Xing L, Fracassi F, Lee H, et al. Coronary plaque characteristics in patients with diabetes mellitus who presented with acute coronary syndromes. J Am Heart Assoc. 2018;7(14):e009245.

7. Kim WJ, Park CY. 1,5-Anhydroglucitol in diabetes mellitus. Endocrine. 2013;43(1):33-40.

8. Fujiwara T, Yoshida M, Yamada H, Tsukui T, Nakamura T, Sakakura K, et al. Lower 1,5-anhydroglucitol is associated with de novo coronary artery disease in patients at high cardiovascular risk. Heart Vessels. 2015;30(4):469-76.

9. Ikeda N, Hara H, Hiroi Y. 1,5-Anhydro-D-glucitol predicts coronary artery disease prevalence and complexity. J Cardiol. 2014;64(4):297-301.

10. Selvin E, Rawlings A, Lutsey P, Maruthur N, Pankow JS, Steffes M, et al. Association of 1,5-anhydroglucitol with cardiovascular disease and mortality. Diabetes. 2016;65(1):201-8.

11. Takahashi S, Shimada K, Miyauchi K, Miyazaki T, Sai E, Ogita M, et al. Low and exacerbated levels of 1,5-anhydroglucitol are associated with cardiovascular events in patients after first-time elective percutaneous coronary intervention. Cardiovasc Diabetol. 2016;15(1):145.

12. Ouchi S, Shimada K, Miyazaki T, Takahashi S, Sugita Y, Shimizu M, et al. Low 1,5-anhydroglucitol levels are associated with long-term cardiac mortality in acute coronary syndrome patients with hemoglobin A1c levels less than 7.0. Cardiovasc Diabetol. 2017;16(1):151.

13. Ma T, Zhou B, Hsiai TK, Shung KK. A review of intravascular ultrasoundbased multimodal intravascular imaging: the synergistic approach to characterizing vulnerable plaques. Ultrason Imaging. 2016;38(5):314-31.

14. Tian J, Ren $X$, Vergallo R, Xing L, Yu H, Jia H, et al. Distinct morphological features of ruptured culprit plaque for acute coronary events compared to those with silent rupture and thin-cap fibroatheroma: a combined optical coherence tomography and intravascular ultrasound study. J Am Coll Cardiol. 2014;63(21):2209-16. 
15. Hong YJ, Jeong MH, Choi YH, Ko JS, Lee MG, Kang WY, et al. Plaque characteristics in culprit lesions and inflammatory status in diabetic acute coronary syndrome patients. JACC Cardiovasc Imaging. 2009;2(3):339-49.

16. Akanuma Y, Morita M, Fukuzawa N, Yamanouchi T, Akanuma H. Urinary excretion of 1,5-anhydro-D-glucitol accompanying glucose excretion in diabetic patients. Diabetologia. 1988;31(11):831-5.

17. Kiniwa N, Okumiya T, Tokuhiro S, Matsumura Y, Matsui H, Koga M. Hemolysis causes a decrease in $\mathrm{HbA} 1 \mathrm{c}$ level but not in glycated albumin or 1,5-anhydroglucitol level. Scand J Clin Lab Investig. 2019:79(6):377-80.

18. Lorenzo-Almorós A, Hang T, Peiró C, Soriano-Guillén L, Egido J, Tuñón J, et al. Predictive and diagnostic biomarkers for gestational diabetes and its associated metabolic and cardiovascular diseases. Cardiovasc Diabetol. 2019;18(1):140.

19. Kim HO, Kim CJ, Kim W, Cho JM, Soeda T, Takano M, et al. Relative risk of plaque erosion among different age and sex groups in patients with acute coronary syndrome. J Thromb Thrombolysis. 2020;49(3):352-9.

20. Niccoli G, Montone RA, Di Vito L, Gramegna M, Refaat H, Scalone G, et al. Plaque rupture and intact fibrous cap assessed by optical coherence tomography portend different outcomes in patients with acute coronary syndrome. Eur Heart J. 2015:36(22):1377-84.

21. Sheng Z, Zhou P, Liu C, Li J, Chen R, Zhou J, et al. Relationships of coronary culprit-plaque characteristics with duration of diabetes mellitus in acute myocardial infarction: an intravascular optical coherence tomography study. Cardiovasc Diabetol. 2019;18(1):136.

22. Dungan KM, Buse JB, Largay J, Kelly MM, Button EA, Kato S, et al. 1,5-anhydroglucitol and postprandial hyperglycemia as measured by continuous glucose monitoring system in moderately controlled patients with diabetes. Diabetes Care. 2006;29(6):1214-9.

23. Wang $Y$, Zhang $Y L$, Wang $Y$ P, Lei $C H$, Sun ZL. A study on the association of serum 1,5-anhydroglucitol levels and the hyperglycaemic excursions as measured by continuous glucose monitoring system among people with type 2 diabetes in China. Diabetes Metab Res Rev. 2012;28(4):357-62.

24. Wada H, Dohi T, Miyauchi K, Takahashi N, Endo H, Kato Y, et al. Impact of serum 1,5-anhydro-D-glucitol level on the prediction of severe coronary artery calcification: an intravascular ultrasound study. Cardiovasc Diabetol. 2019;18(1):69.

25. Reith S, Milzi A, Lemma ED, Dettori R, Burgmaier K, Marx N, et al. Intrinsic calcification angle: a novel feature of the vulnerable coronary plaque in patients with type 2 diabetes: an optical coherence tomography study. Cardiovasc Diabetol. 2019;18(1):122

26. Ceriello A, Monnier L, Owens D. Glycaemic variability in diabetes: clinical and therapeutic implications. Lancet Diabetes Endocrinol. 2019;7(3):221-30.

27. Zhang T, Su G, Mi SH, Yang HX, Xin W, Dai WL, et al. Association between blood glucose variability and the characteristics of vulnerable plaque in elderly non-st segment elevation acute coronary syndrome patients. Int Heart J. 2019;60(3):569-76.

28. Kohata Y, Ohara M, Nagaike H, Fujikawa T, Osaka N, Goto S, et al. Association of hemoglobin $A_{1 c}$ 1,5-anhydro-D-glucitol and glycated albumin with oxidative stress in type 2 diabetes mellitus patients: a cross-sectional study. Diabetes Ther. 2020;11(3):655-65.

29. Pignatelli P, Menichelli D, Pastori D, Violi F. Oxidative stress and cardiovascular disease: new insights. Kardiol Pol. 2018;76(4):713-22.

30. Su G, Wang T, Zhang T, Yang HX, Yu SS, Dai WL, et al. Urinary 8-isoprostaglandin $\mathrm{F}_{2 \mathrm{a}}$ as a risk marker for the vulnerability of culprit plaque in diabetic patients with stable coronary artery disease. Prostaglandins Leukot Essent Fatty Acids. 2019;140(1):11-7.

31. Nishibe A, Kijima Y, Fukunaga M, Nishiwaki N, Sakai T, Nakagawa Y, et al. Increased isoprostane content in coronary plaques obtained from vulnerable patients. Prostaglandins Leukot Essent Fatty Acids. 2008;78(4-5):257-63.

32. Yura T, Fukunaga M, Khan R, Nassar GN, Badr KF, Montero A. Free-radicalgenerated F2-isoprostane stimulates cell proliferation and endothelin-1 expression on endothelial cells. Kidney Int. 1999;56(2):471-8.

33. Esposito K, Nappo F, Marfella R, Giugliano G, Giugliano F, Ciotola M, et al. Inflammatory cytokine concentrations are acutely increased by hyperglycemia in humans: role of oxidative stress. Circulation. 2002;106(16):2067-72.

34. Teraguchi I, Imanishi T, Ozaki Y, Tanimoto T, Orii M, Shiono Y, et al. Impact of glucose fluctuation and monocyte subsets on coronary plaque rupture. Nutr Metab Cardiovasc Dis. 2014;24(3):309-14.

\section{Publisher's Note}

Springer Nature remains neutral with regard to jurisdictional claims in published maps and institutional affiliations.
Ready to submit your research? Choose BMC and benefit from:

- fast, convenient online submission

- thorough peer review by experienced researchers in your field

- rapid publication on acceptance

- support for research data, including large and complex data types

- gold Open Access which fosters wider collaboration and increased citations

- maximum visibility for your research: over $100 \mathrm{M}$ website views per year

At BMC, research is always in progress.

Learn more biomedcentral.com/submissions 